\title{
Study of dissolve oxygen, salinity and temperature around western offshore- A case study around North Bombay of ONGC's offshore Filed, Arabian Sea, India
}

\author{
Rajkumar Mandal * and Gada Lal Das \\ Institute of Petroleum Safety, Health and Environment Management, Oil and Natural Gas Corporation Limited, Goa, India
}

World Journal of Advanced Engineering Technology and Sciences, 2021, 02(01), 091-100

Publication history: Received on 05 February 2021; revised on 10 March 2021; accepted on 12 March 2021

Article DOI: https://doi.org/10.30574/wjaets.2021.2.1.0017

\begin{abstract}
Marine ecosystems cover approximately $71 \%$ of the Earth's surface and contain approximately $97 \%$ of the planet's water. Dissolve oxygen, which is a vital parameter in Ocean's primary production, is having a sensitive integrating property reflecting physical and biogeochemical changes in the marine environment. The other parameters like temperature, though conservative, has a great impact upon biological productivity and salinity is important to understand the dynamics of water column. By analyzing the variation of dissolve oxygen, temperature and salinity, environmental status of that particular study area can be assessed. As a preventive measure to protect water bodies, Oil and Natural Gas Corporation Limited, India is regularly conducting Offshore Environment Monitoring around western continental shelf of Arabian Sea, where ONGC's Platforms and Installations are located.

The paper includes the output of monitoring activities of ONGC around north Bombay considering these three parameters i.e. temperature, salinity and dissolved oxygen for assessing the environmental health of the study area. A trend analysis of the three parameters around North Bombay of ONGC's offshore Filed (NA \& NQ platform) has been done considering the monitoring data from the year 2017-18 to 2020-21 and their variation has been studied. It has been observed from the study that there is an increasing trend of dissolve oxygen and salinity for both platform (NA \& NQ). It is observed that trend of temperature for NA platform is decreasing whereas around NQ it is increasing. The mean values of three parameters are comparable with reference mean values and the variations are insignificant.
\end{abstract}

Keywords: Dissolve Oxygen (D0); Temperature; Salinity; Arabian Sea; ONGC

\section{Introduction}

Dissolved oxygen concentration is affected by physical, chemical and biological processes. Factors which cause an increase in dissolved oxygen concentration are photosynthesis, diffusion from the sea surface, and mainly the action of the wind and the currents which by causing surface water turbulence, saturate the surface layers with oxygen. Reduction of dissolved oxygen concentration is caused by the respiration of marine organisms and by the oxidation of organic substances either by simple chemical reactions or by bacterial activity. High temperatures and high salinity values lead to a reduction in oxygen solubility. Nearly all living organisms need oxygen in order to carry out their biological processes. However, the quantity of oxygen demanded differs according to species, mode of life, sex, age as well as environmental factors such as temperature, salinity and the presence of various types of pollutants

After discovery of Bombay High in 1974, ONGC has deployed several drilling rigs and commissioned process platforms besides more than a hundred unmanned platforms in Western continental shelf. As per its own self control strategies and commitment to protect marine environment, ONGC started regular environment monitoring of its oil fields and installations around Western Offshore areas. IPSHEM, a pioneer institute of ONGC to take care of the Safety, Health and

* Corresponding author: Rajkumar Mandal

IPSHEM, ONGC, Goa, India.

Copyright (C) 2021 Author(s) retain the copyright of this article. This article is published under the terms of the Creative Commons Attribution Liscense 4.0. 
Environmental needs of the petroleum sector, is carrying out the monitoring job of the important environmental parameters since 1994-95.

With the help of trend analysis of dissolved oxygen, temperature and salinity from 2017-18 to 2020-21, the paper tries to analyze the relationship of these three parameters and focuses its implications on marine environment.

\section{Material and methods}

\subsection{Study Area}

The study area is covering around north Bombay of ONGC's offshore field (NA \& NQ platform) in the Western continental shelf is shown as bellow. Map showing the location of sampling stations in the study area of Western offshore (Fig.1). Latitude and longitude of NA and NQ platforms are mentioned in table.1.

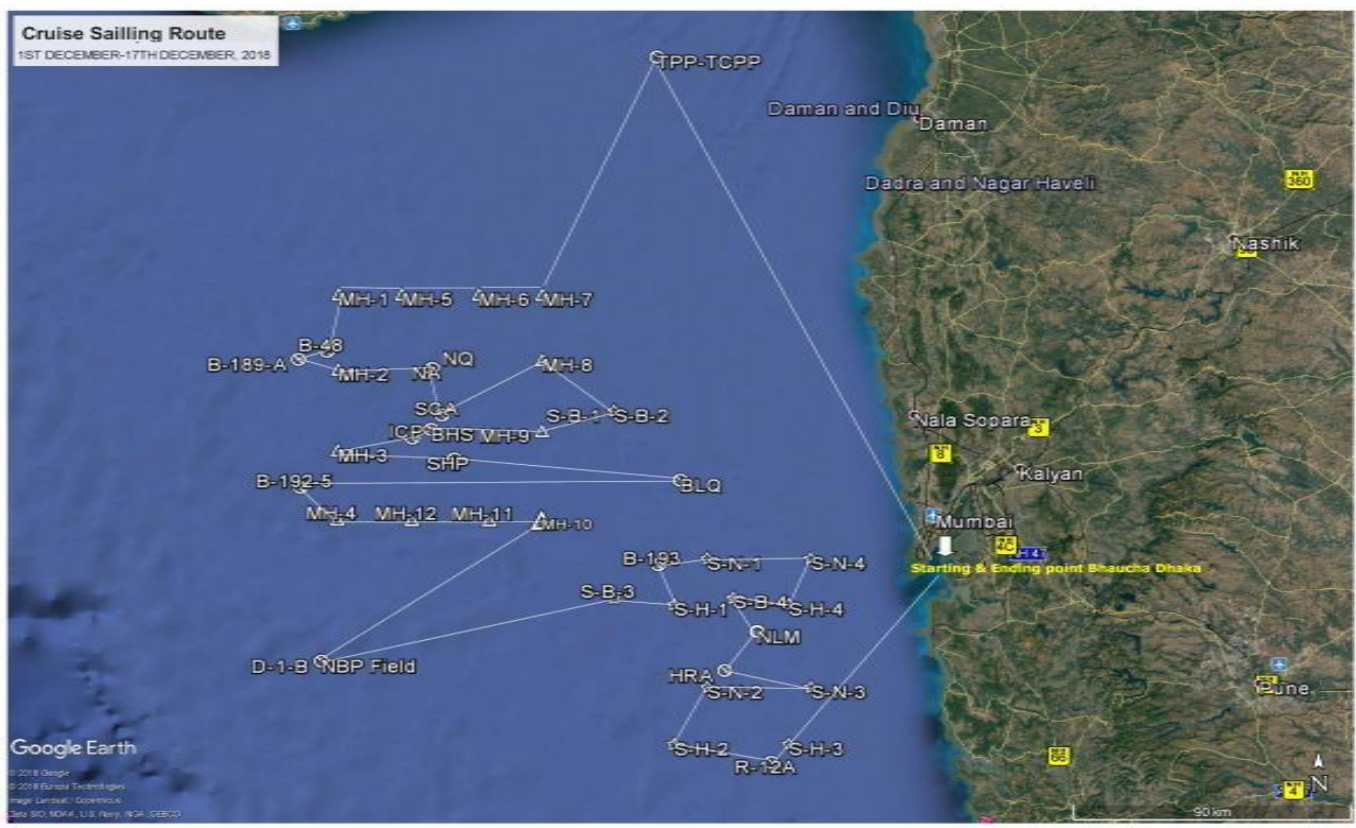

Figure 1 Sampling stations in the study area of Western offshore

\begin{tabular}{|l|l|l|}
\hline Platform & $\begin{array}{l}\text { Latitude } \\
\text { (N) }\end{array}$ & $\begin{array}{l}\text { Longitude } \\
\text { (E) }\end{array}$ \\
\hline NA & $19^{0} 34.25^{\prime}$ & $71^{0} 21.54^{\prime}$ \\
\hline NQ & $1^{\circ} 34.25^{\prime}$ & $71^{0} 21.54^{\prime}$ \\
\hline
\end{tabular}

\subsection{Field sampling}

Samples were collected according to OSPAR guideline (Fig 1) [1]. 18 sampling stations were fixed around each installation at circle of radios from $250 \mathrm{~m}$ to 4000 mfrom the centre of installation. Reference point was fixed approximately $10 \mathrm{~km}$ awayfrom installation point. 


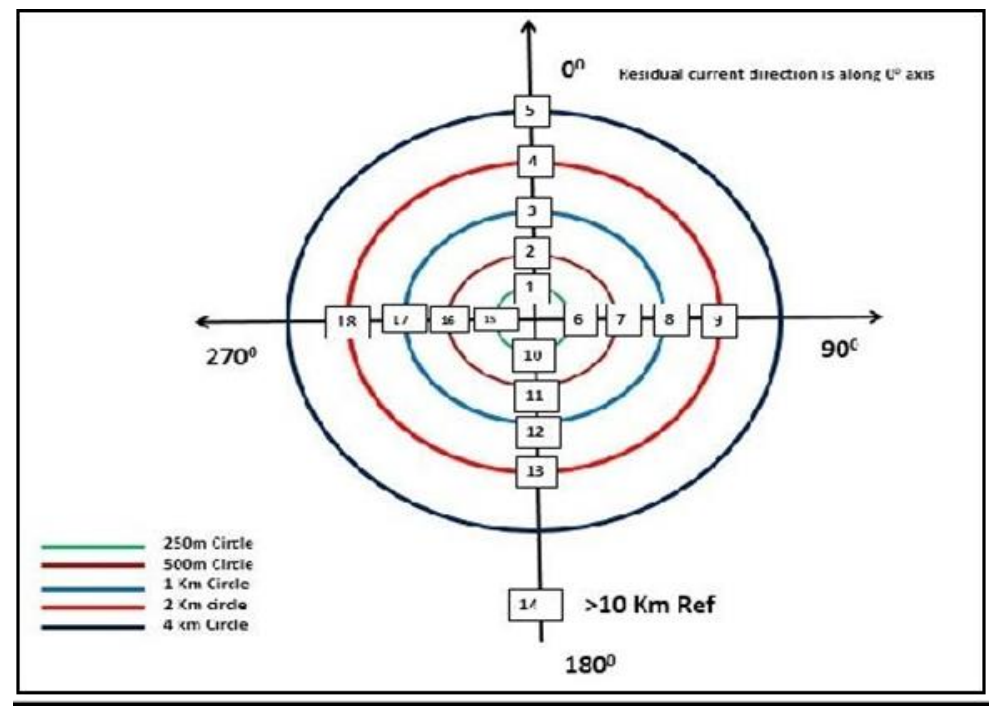

Figure 2 Field sampling

\subsection{Sample analysis}

Parameters like temperature, salinity, dissolved oxygen are determined, onboard the vessel, using the CTD profiler and the values were double-checked using manual methods.

\subsubsection{Dissolve Oxygen}

Dissolved Oxygen (DO) was measured directly by SYSTRONICS water analyser with an accuracy of $0.1 \mathrm{ppm}$. The values of DO are expressed in $\mathrm{mg} / \mathrm{l}$.

\subsubsection{Temperature}

Temperature was measured using the centigrade thermometer with a graduation of 0 - $1000 \mathrm{C}$. This is an important parameter since the characteristics of water column like the density, viscosity, solubility, of gases and dissolved oxygen are related to temperature of the water column. The variation in temperature of a water body has great impact upon the biological productivity. The organism including fishes show limited tolerance for variation in temperature for processes such as feeding, reproduction and movement. Distribution of aquatic organism is greatly influenced by water temperature.

During the survey it was revealed that the water column experienced homogeneous and uniform distribution of temperature indicating that the impact of the offshore operation on the thermal regime of the water column is insignificant.

\subsubsection{Salinity}

Salinity was measured directly by SYSTRONICS water analyzer with an accuracy of $0.1 \mathrm{ppt}$. Prior to the sample, standard seawater was used to calibrate the salinometer.

\section{Results and discussion}

\subsection{Dissolved Oxygen (DO)}

Dissolved oxygen is one of the essential and very important parameters in assessing the health of aquatic environment. Mean values of DO around NA platform varies from $5.4 \mathrm{mg} / \mathrm{l}$ to $5.71 \mathrm{mg} / \mathrm{l}$ and trend shows increasing during period 2017-18 to 2020-21[2] (Fig 3). Around NQ platform mean values of DO varies from $5.27 \mathrm{mg} / \mathrm{l}$ to $5.90 \mathrm{mg} / \mathrm{l} \mathrm{overall} \mathrm{trend}$ shows increasing [2] (Fig 4). Reference values of both platform are comparable with mean DO values [2] (Fig 5 \& Fig 6). 


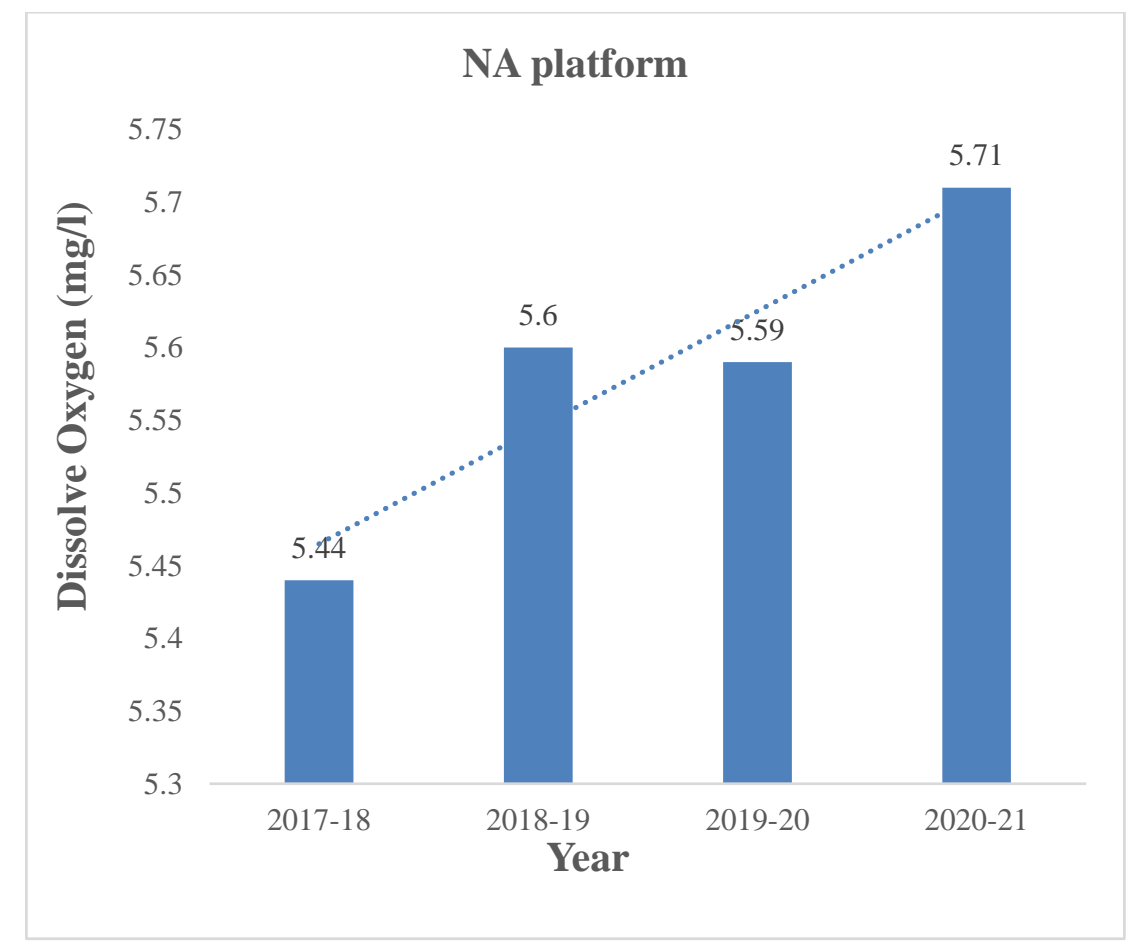

Figure 3 Trend analysis of Dissolve Oxygen around NA platform.

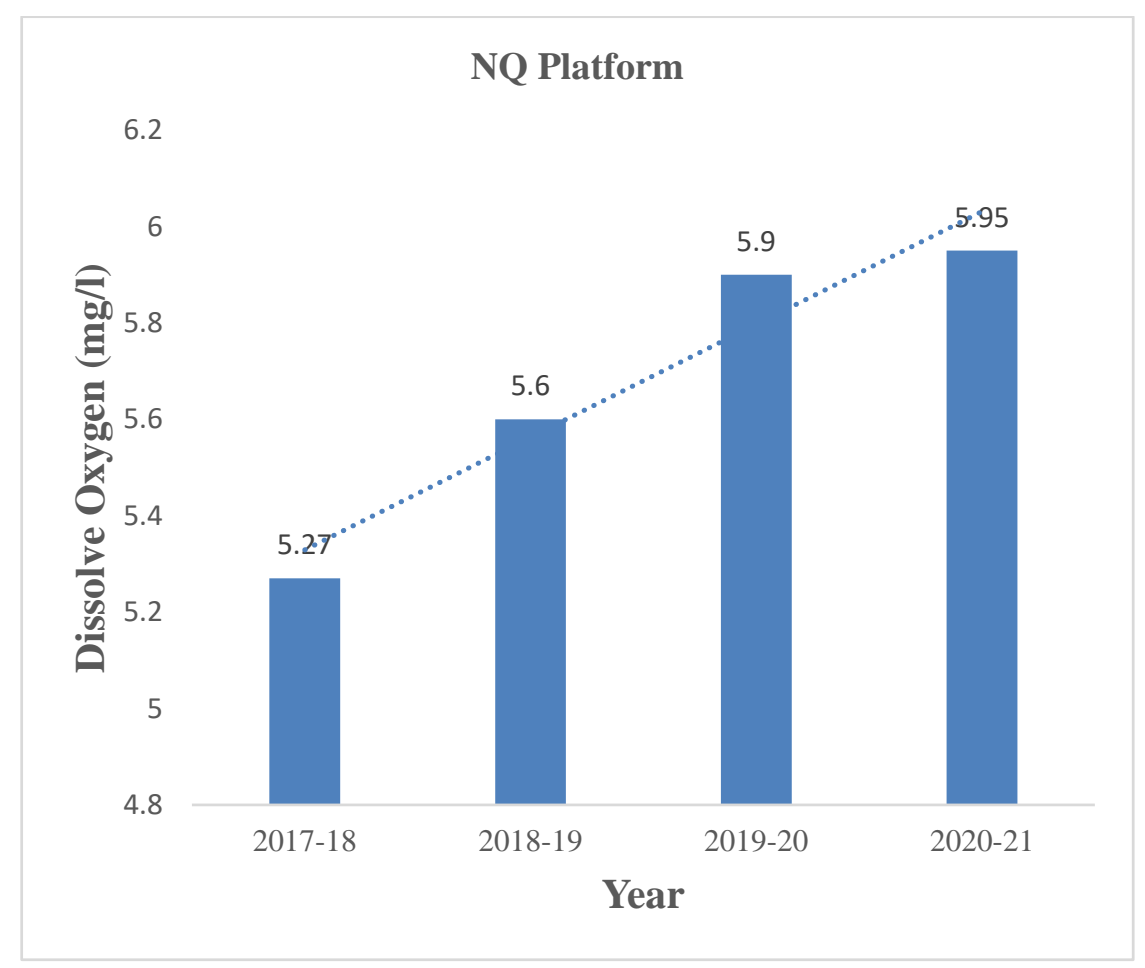

Figure 4 Trend analysis of Dissolve Oxygen around NQ platform. 


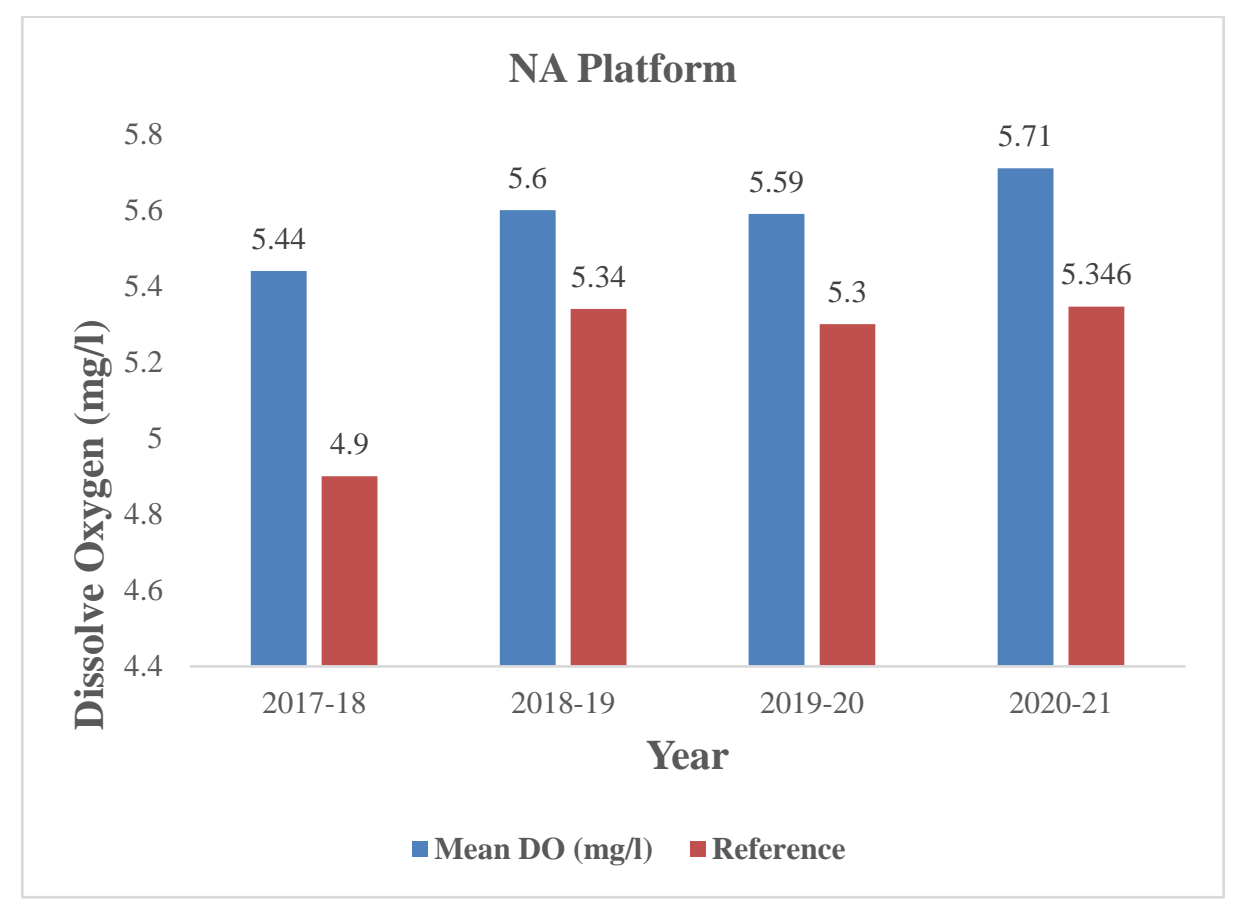

Figure 5 Comparison of mean DO with reference for NA platform.

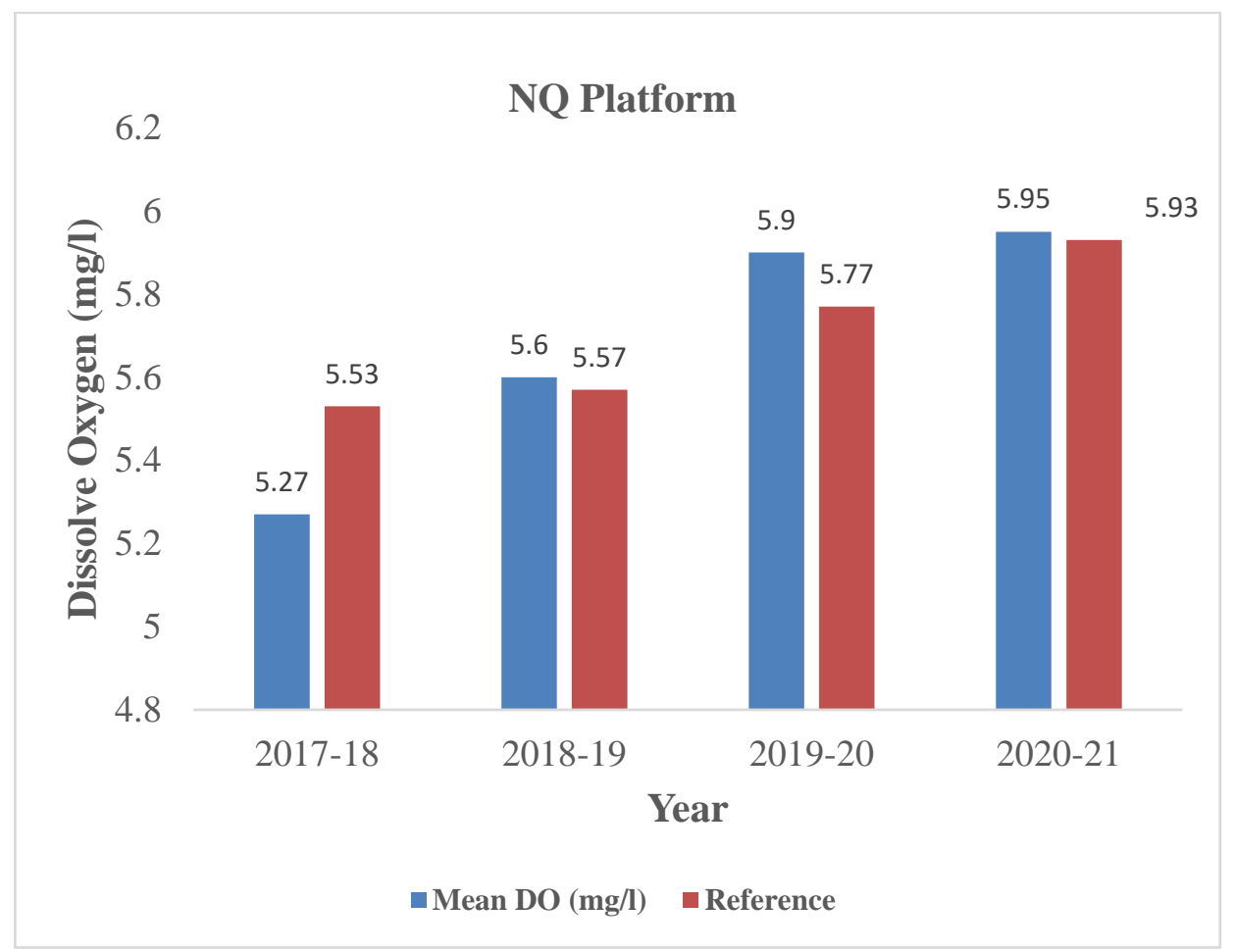

Figure 6 Comparison of mean DO value with reference for NQ platform. 


\subsection{Temperature}

The mean sea temperature around NA platform varies $25.6{ }^{\circ} \mathrm{C}$ to $26.9{ }^{\circ} \mathrm{C}$ whereas for NQ platform varies $26{ }^{\circ} \mathrm{C}$ to 26.47 ${ }^{0} \mathrm{C}$ during period 2017-18 to 2020-21[2]. It has been observed increasing trend of temperature during the study period around NA platform (Fig 7) and reverse trend around NQ platform (Fig 8). It is shown that reference values are comparable with mean values [2] (Fig 9 \&Fig 10).

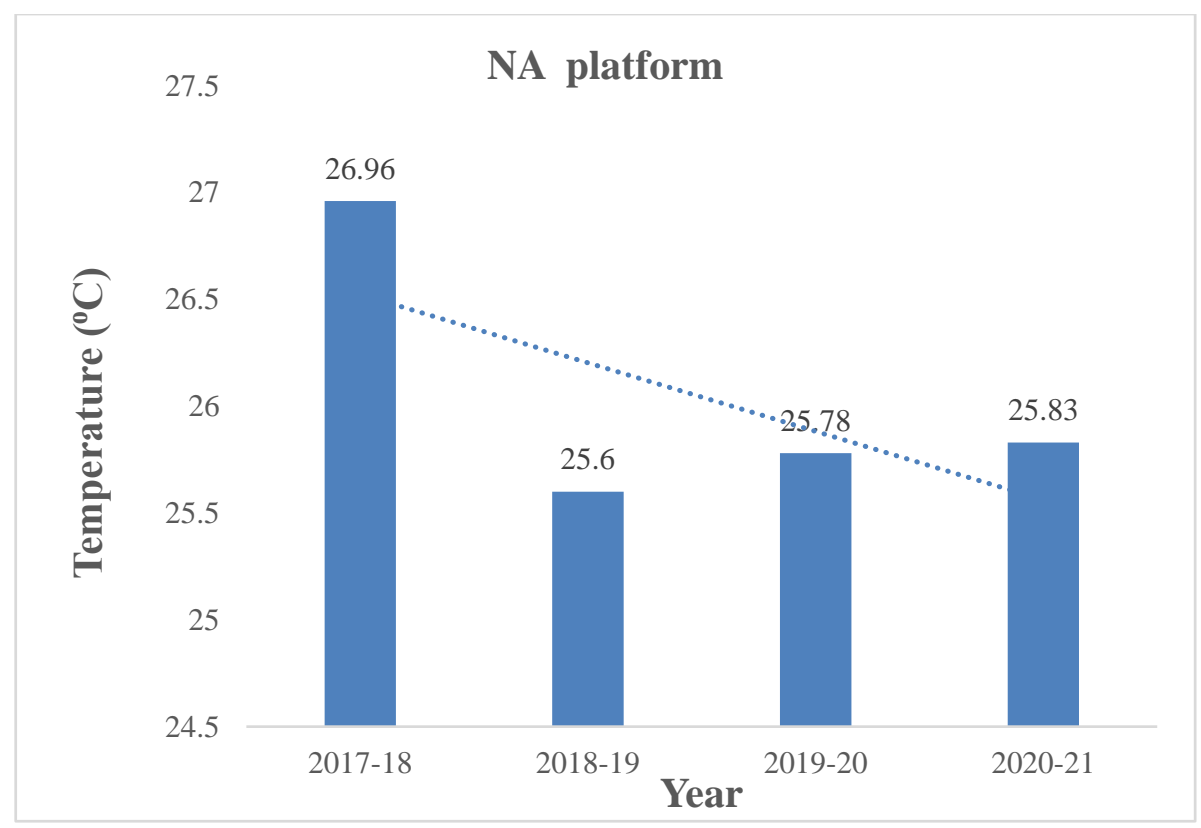

Figure 7 Trend analysis of Temperature around NA platform.

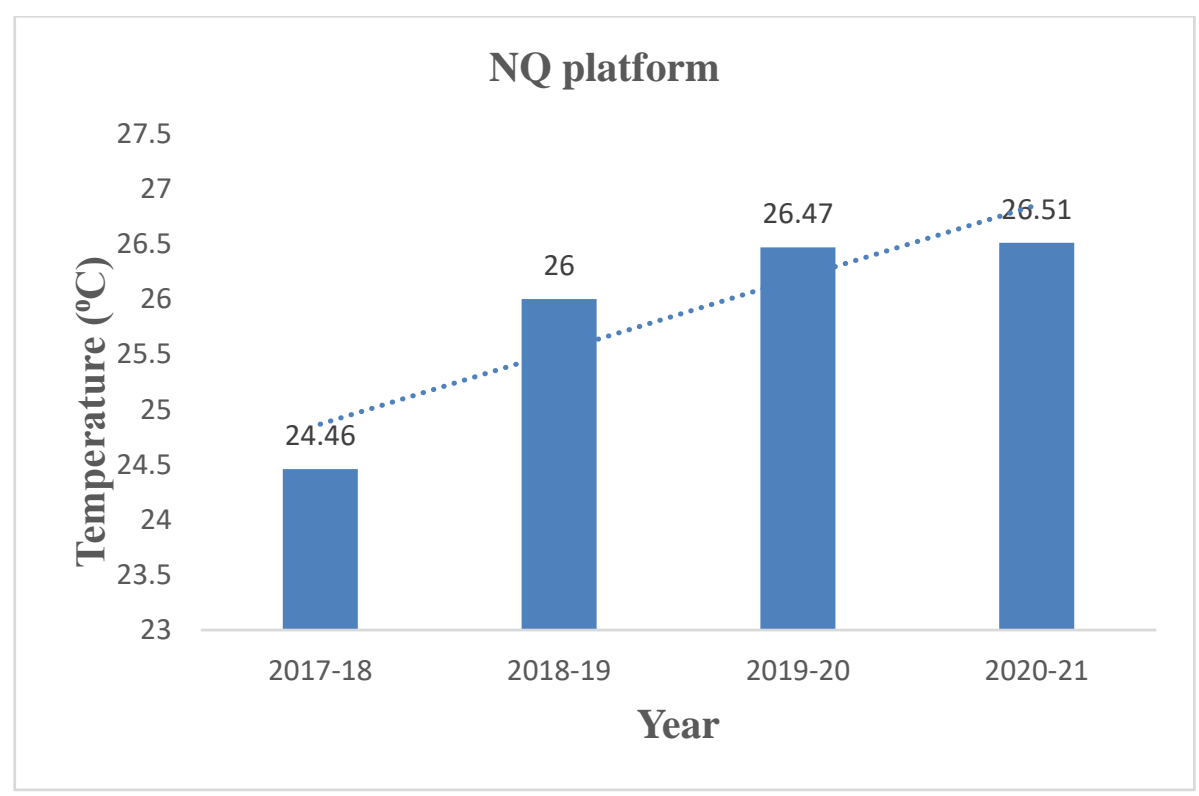

Figure 8 Trend analysis of Temperature around NQ platform. 


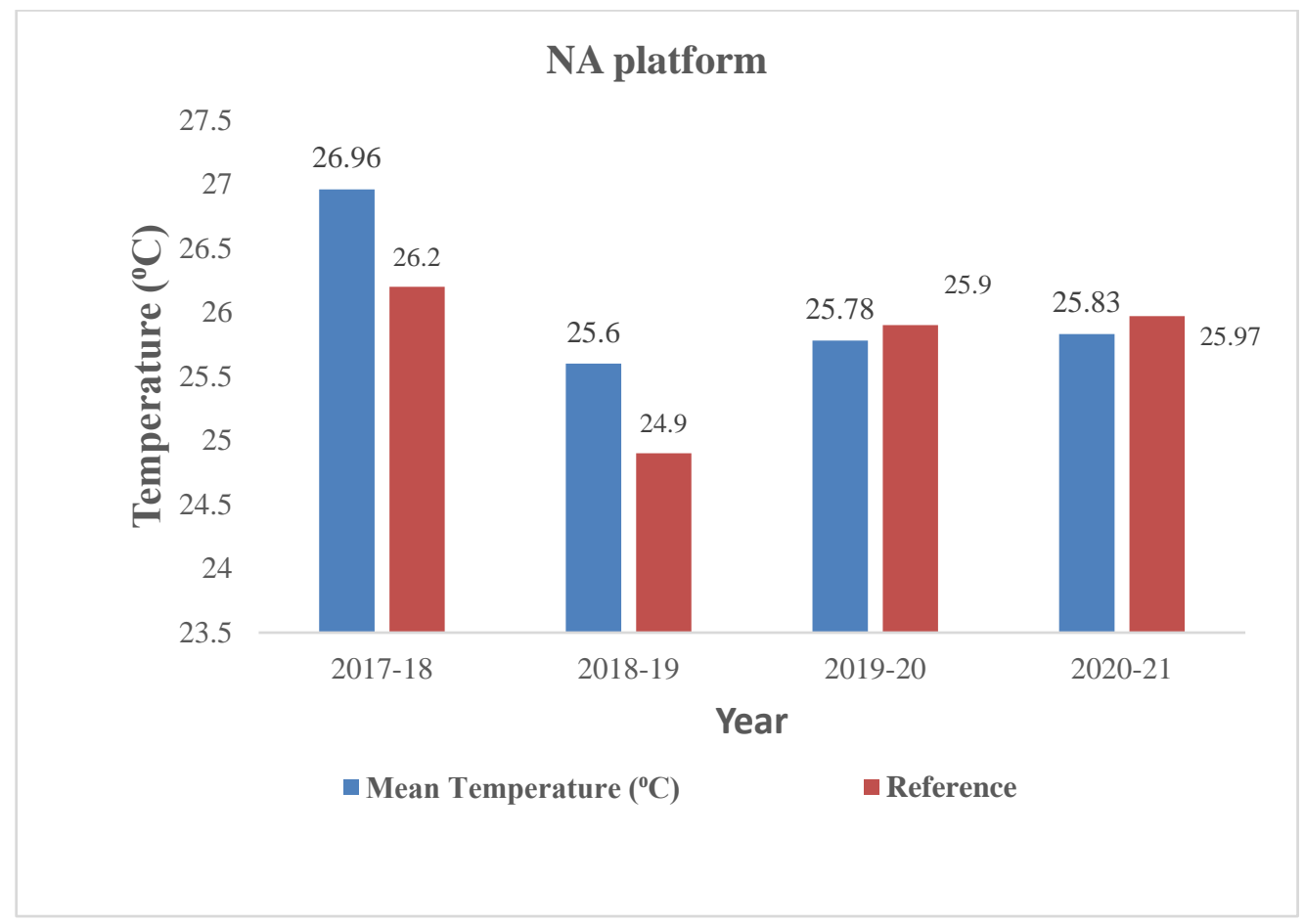

Figure 9 Comparison of mean Temperature $\left({ }^{0} \mathrm{C}\right)$ with reference for NA platform.

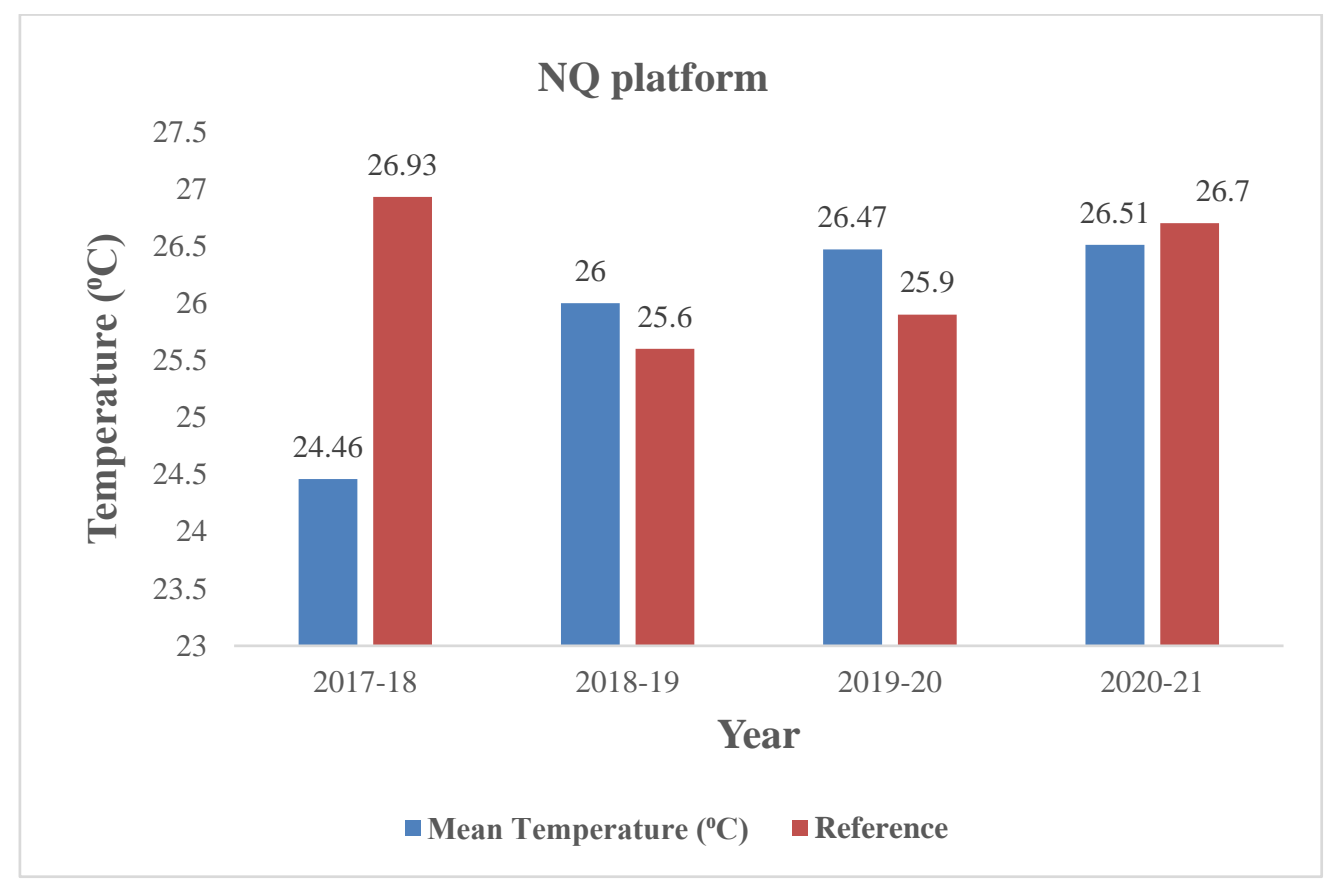

Figure 10 Comparison of mean Temperature $\left({ }^{0} \mathrm{C}\right)$ with reference for NQ platform. 


\subsection{Salinity}

Data presented in Fig 11 reveals a variation of mean values in salinity form 32.61 PSU to 36.46 PSU and overall trend is showing increasing around NA platform during period of 2017-18 to 2020-21[2]. Around NQ platform mean values in salinity varies 33.25 PSU to 36.66 PSU (Fig 12) and trend is showing increasing [2]. It has been observed that mean salinity values almost comparable with reference values [2] (Fig 13 \&Fig 14).

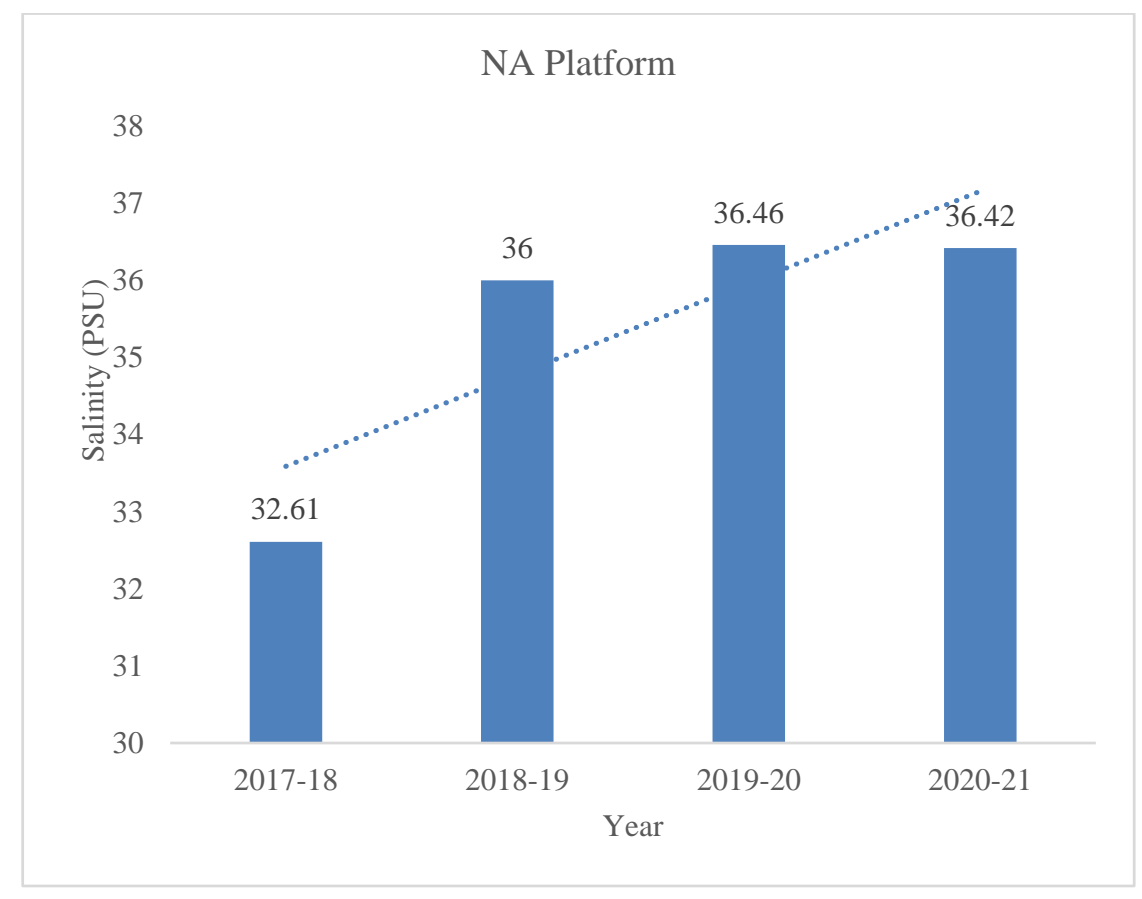

Figure 11 Trend analysis of salinity around NA platform.

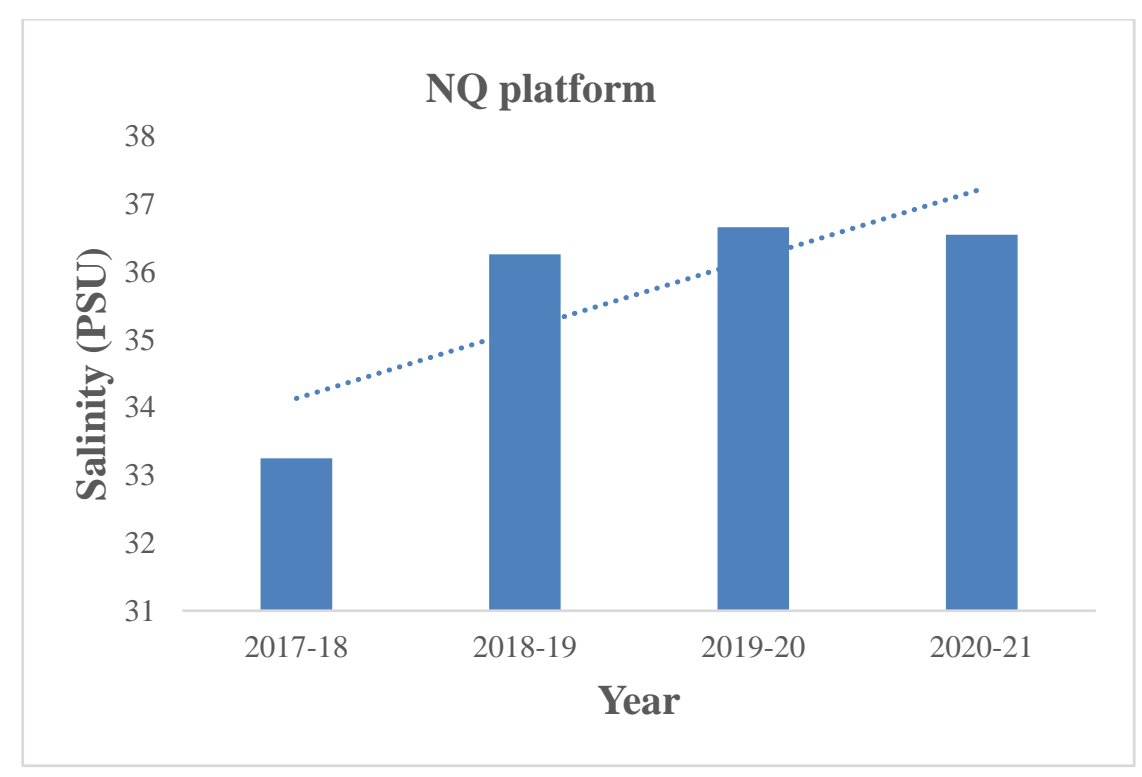

Figure 12 Trend analysis of Temperature around NQ platform. 


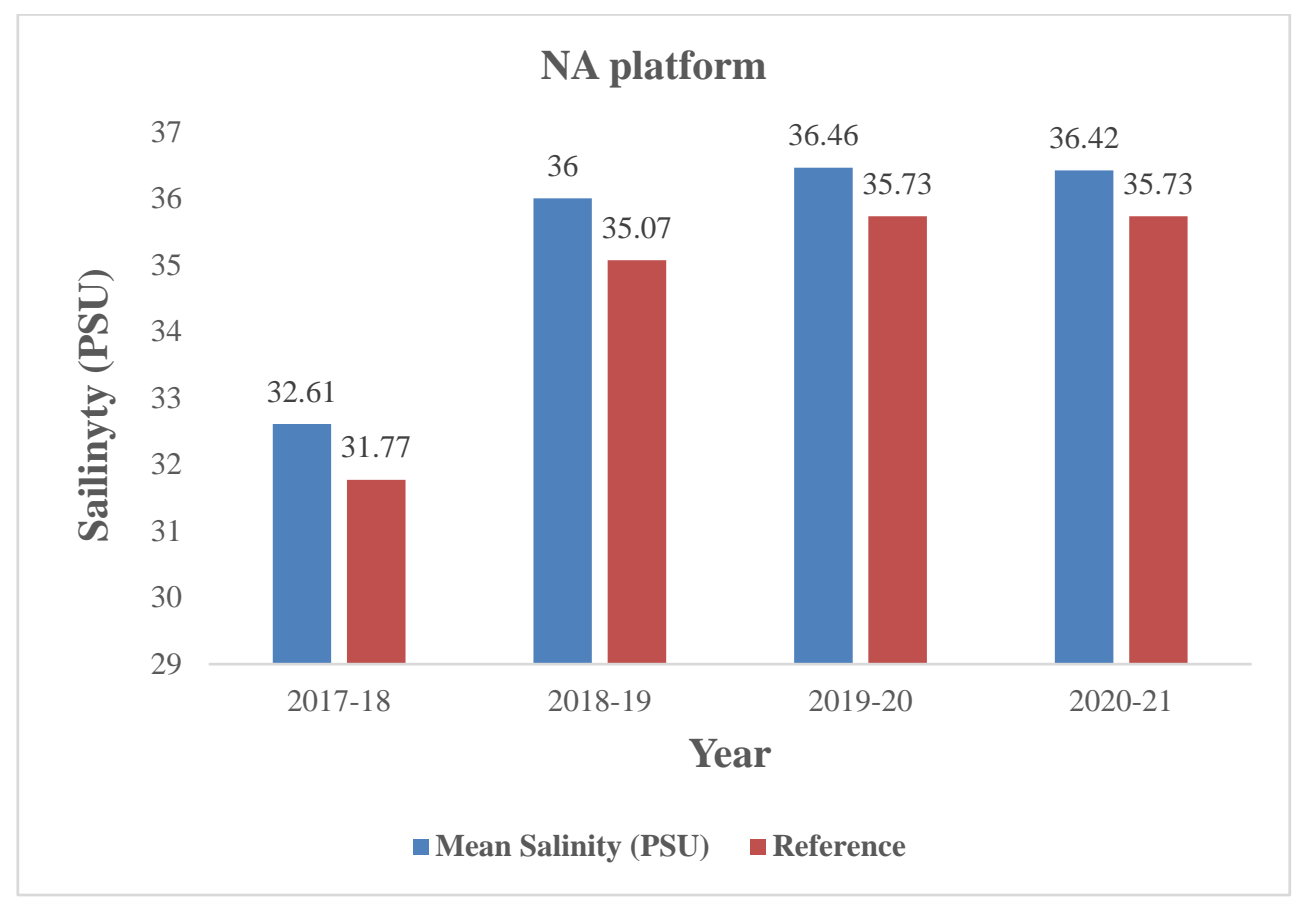

Figure 13 Comparison of mean Temperature $\left({ }^{0} \mathrm{C}\right)$ with reference for NA platform.

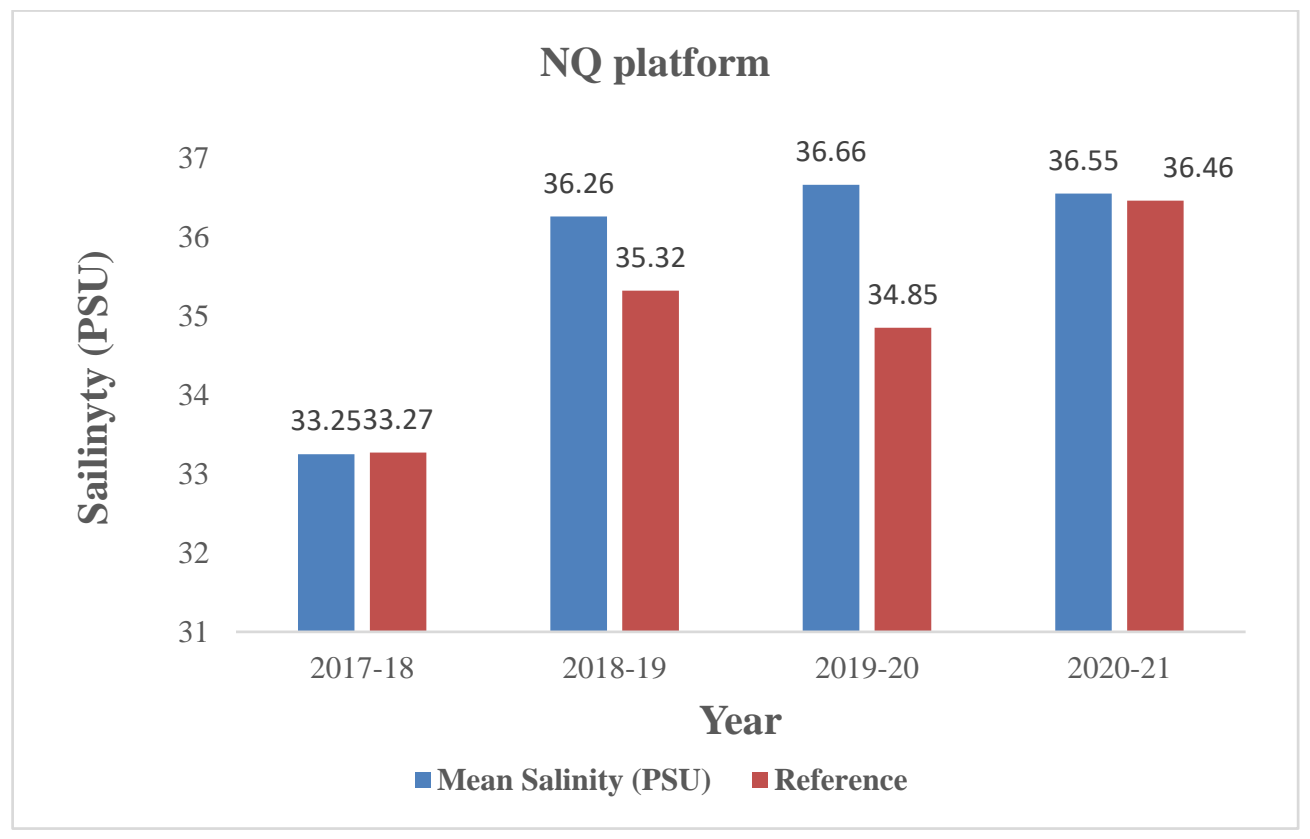

Figure 14 Comparison of mean Temperature $\left({ }^{0} \mathrm{C}\right)$ with reference for NQ platform. 


\section{Conclusion}

The paper includes the output of monitoring activities of ONGC considering variation of these three environmental parameters for assessing the influence of E\&P activities on marine environment. The trend analysis results from 201718 to 2020-21 show that the values are comparable with reference values and almost remain constant throughout year around ONGC installation. The variations are very much insignificant. It has been observed from the study that values of these parameters are well within range of oceanographic range over the years and no particular trend is observed. Primary production is not disturbed by exploration and production activities of ONGC's offshore operations. Therefore, sea water in Arabian Sea around NA and NQ platforms is not polluted with respect to these parameters.

\section{Compliance with ethical standards}

\section{Acknowledgments}

The authors are extremely grateful to ONGC's management for their encouraging in preparation of this paper. They also wish to ED-HOI, IPSHEM, ONGC, Goa for his continuous guidance and support.

\section{Disclosure of conflict of interest}

The authors declare no conflict of interest.

\section{References}

[1] Paris commission Guidelines for monitoring methods to be used in the vicinity of platforms in the North Sea, Paris Commission 1989.

[2] Offshore Environment Monitoring around ONGC installations in Western Offshore Region reports from 2017-18 to $2020-21$. 